\title{
Socio-demographic characteristics and Iodine status of the school-going children of Suryodaya Municipality, Ilam BABITA ADHIKARI ${ }^{*}$ AND PRAJA ADHIKARI ${ }^{1}$ \\ ${ }^{1}$ Department of Nutrition \& Dietetics, Central Campus of Technology, Tribhuvan University, Nepal
}

\begin{abstract}
Iodine Deficiency Disorder (IDD) is a major micronutrient deficiency problem in Nepal. This study was conducted to measure the Urinary Iodine Excretion (UIE) and attempts were made to relate urinary iodine with salt use and other sociodemographic variables of the household of primary school children of Suryodaya municipality of Ilam district of Nepal. A community-based cross-section study was conducted in two schools of study area selected randomly (lottery method). A total of 202 school children of 6-12 years were recruited for the study to collect urine and salt samples for Urine Iodine Content (UIC) and Salt Iodine Content (SIC) measurement respectively and detail information of the study population was achieved from their household. UIC was measured by ammonium persulphate digestion microplate (APDM) method and SIC was estimated by rapid test kit (RTK). Data were expressed in frequency, mean $\pm S D$, and median (IQR) according to the nature of data. Chi-square test, Mann-Whitney U test, and Kruskal-Wallis test were used to test the significance considering $p \leq 0.05$ at $95 \%$ confidence interval. It was found that the Median UIC of the study population was $152.14 \mu \mathrm{g} / \mathrm{L}$. Overall; it was found that $30.7 \%$ of children had a urine iodine level less than the normal WHO levels. The availability of adequately iodized salt was $93.1 \%$ as measured by RTK. There was a statically significant association between consumed salt iodine content and urine iodine excretion level $(P<0.05)$.
\end{abstract}

Keywords: Iodine deficiency disorder, urinary iodine excretion, urine iodine content, salt iodine content

\section{Introduction}

Iodine is a micronutrient which is essential for human growth and normal functioning of the body and is needed in very small quantity regularly. Iodine deficiency is a major public health problem throughout the world, particularly in developing countries. A deficiency of iodine leads to hypothyroidism, impaired mental and physical development in infants, children and adolescents, goiter, impaired mental function and reduced productivity in adults (UNCEF,2002) and an increased risk of spontaneous abortion, stillbirths, and congenital abnormalities in pregnancy (WHO, 2012).

World Health Organization (WHO) estimated the worldwide prevalence of iodine deficiency using urinary iodine excretion (UIE) data collected for $92 \%$ of the world's population in the period from 1993 to 2003. Nearly two billion individuals have inadequate (UIE $<100$ $\mu \mathrm{g} / \mathrm{L}$ ) iodine nutrition, and the occurrence of iodine deficiency was observed in $36.4 \%$ of school-going children (WHO, 2007). Iodine deficiency is a major public health problem in Nepal, $19.4 \%$ of school-going children are at risk. The prevalence of iodine deficiency in hilly and plain regions is $18.9 \%$ and $9.5 \%$ respectively shown by previous studies (Gelal et al., 2010). The age group recommended by WHO for IDD survey was $6-12$ years. This age group was recommended to be used in the surveys in all the countries because children in this age group have a high vulnerability, easy access, and also, affected children develop an enlarged thyroid, in response to iodine deficiency and can be readily examined in large numbers in school settings (ICCIDD et al., 2007) and as a representation of iodine deficiency in the community (Biswas et al.,2006). " Several attempts have been made by the Government of Nepal to combat IDD by fortifying salt with iodine, but the problem still persist, especially in Hilly and Mountainous region of Nepal"(MoHP, 2005 \& 2007). This study is designed to access iodine nutrition status in Suryodaya municipality of Ilam by using different indicators i.e. UIE and Salt Iodine Content (SIC).

\section{Materials and methods \\ Research design}

The cross-sectional design was used to collect primary data from the selected sample by taking urine and salt samples of school-going children; household survey with the help of semi-structured questionnaires.

\section{Study area}

Study area was Suryodaya municipality of Ilam (VDCsPhikkal, Panchakanya, and Kanyam), Nepal which has an elevation of $5135 \mathrm{ft}$ with the total population of 17,240.

\section{Descriptive statistics of schools}

Out of a total of 202 school going children, 127(62.9\%) children were enrolled from Saijyoti English Boarding school and 75 (37.1\%) from Shree Krishna Uchha Ma Vi. A total of $121(59.9 \%)$ were boys and 81 (40.1\%) were girls.

\footnotetext{
Study variable

Dependent variable were Urinary Iodine Excretion and Salt Iodine content and Independent variables are socioeconomic and demographic variables (head of households, ethnicity, religion, family size, income, education, occupation); Child characteristics (age, sex, height weight); Kitchen practices (a type of salt, type of salt container, time of adding salt while cooking, place of the store).
} 


\section{Sampling technique and target population}

A simple random sampling procedure (lottery method) was used in the study. Two schools were randomly selected from the community. All school children (age group 6-12) from class 1 to 5 were selected as a study population. The total sample size was 202 .

\section{Exclusion criteria}

Schools having the current history of micronutrient supplements, Children having a severe illness, Children who did not want to participate in the study

\section{Sample size}

The calculation of the sample size was done by using the statistical formula,

$\mathrm{n}=\mathrm{t}^{2}$. P. (1-P) / $\mathrm{m}^{2}$

Where, $\mathrm{n}=$ required sample size, $\mathrm{t}=$ confidence interval at 95\% (standard value of 1.96), $\mathrm{p}=$ estimated prevalence of IDD, $\mathrm{m}=$ margin of error at $5 \%$ (standard value of 0.05 ) (Galel et al., 2009).

\section{Research instrument}

Equipment needed for performing the survey were: Child weighing machines (Seca scale):- Child weighing machines having a capacity of $100 \mathrm{~kg}$; Height measuring stand (Stadiometer):- The height measuring tape of $5 \mathrm{ft}$ capacity; Questionnaire: - A well-designed set of questionnaire to collect information on household characteristics, food availability and its consumption, health facility, etc.; Urine vile, plastic pouch for salt collection, rapid iodine test kit and icebox; Instrument used during analysis: Multi pipette, Sealing cassette, Microtitre reader.

\section{Pre-testing}

The pre-testing was conducted to establish the accuracy of the questionnaire and to check for consistency in the interpretation of questions and to identify ambiguous items. After a review of instruments, all suggested changes were made before being administered in the actual study.

\section{Validity and reliability}

The instruments were validated by a group of professionals from Department of Nutrition and Dietetics, Central Campus of Technology, The aspects tested in the questionnaire were also drawn from the available literature in nutrition education for young children. The questionnaire was also pre-tested before data collection to ascertain content and face validity. The questionnaire was checked daily for completeness, consistency, and clarity as mentioned earlier.

Data collection techniques: Before the sample collection, the purpose of the visit was explained to the Principal of the School. Students and parents were informed by the Principal regarding the purpose of the study.

\section{Anthropometric measurements include height and weight}

The height of the children was taken using a portable standiometer calibrated in centimeters $(\mathrm{cm})$ without shoes on a flat floor. A good standing posture was maintained before measurement. The heels were pulled together touching the base of the wall. The head was erect and hands naturally hung at their sides. The child's line of sight was in level with the ground for accuracy. The measurements were taken to the nearest $0.1 \mathrm{~cm}$. after the head piece was placed on the head of each subject; the reading was taken to the nearest $0.1 \mathrm{~cm}$.

The weight of the children with minimum clothing was taken using a Salter beam balance to the nearest $0.1 \mathrm{~kg}$. Ages were recorded from the school records on admission.

\section{Salt sample}

Detailed instructions were given to children and were instructed to bring two teaspoonfuls (approximately 15 gram) salt samples from their houses which they used for everyday purposes. Each child was provided a clean, moisture-free, tightly closing plastic pouch to bring the sample prior one day of salt sample collection.

\section{Urine sample}

Spot urine samples were collected from all the eligible children in a clean, numbered, tightly screw-capped 15 milliliters plastic vial. The were transported in an ice pack to the biochemistry laboratory of BPKIHS and were analyzed by using ammonium persulfate digestion microplate method (ICCIDD et al.,2007).

\section{Semi structured questionnaire}

The questionnaires comprised mainly of details on household profiles like age, sex, education level and occupation of household members and household size, type of salt, consumption of goitrogenic food, etc. The interview was conducted with parents/care takers of the children to fill the questionnaire.

\section{Data analysis}

Microsoft Excel and IBM SPSS Statistics version 20.0 were used. Descriptive statistics (Frequency, Mean \& Standard Deviation, and Median \& Inter Quartile Range) and inferential statistics (Chi Square Test, Student's t-test, Mann-Whitney $U$ test, and Kruskal-Wallis test) were applied whenever they needed at $95 \%$ to $99 \%$ significance level.

\section{Chemical analysis of urine sample}

Iodine concentration in the urine sample was measured by the ammonium persulphate digestion microplate method (Galel et al., 2009). Briefly, to $50 \mu \mathrm{L}$ calibrators and urine samples in wells of a microtitre plate, $100 \mu \mathrm{L}$ fresh ammonium persulphate solution $(35 \% \mathrm{w} / \mathrm{v})$ was added. After that, Plate was set in sealing cassette, closed tightly, and was kept in an oven at temperature $110^{\circ} \mathrm{C}$ for $60 \mathrm{~min}$ for digestion. It was then cooled, opened and $50 \mu \mathrm{L}$ 
of digested aliquot was transferred into other

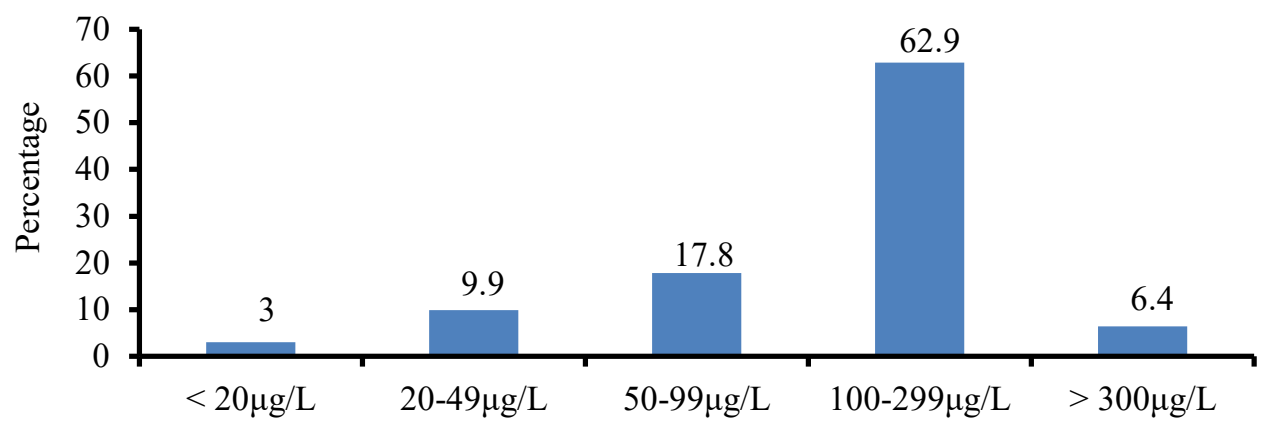

Figure 1. Iodine status of school going children

corresponding wells of the next plate. Then, $100 \mu \mathrm{L}$ arsenious acid solution $(1 \% \mathrm{w} / \mathrm{v}, 0.05 \mathrm{~mol} / \mathrm{L})$ was added to each well and mixed properly followed by addition of $50 \mu \mathrm{L}$ cerric ammonium sulphate solution $(1.2 \% \mathrm{w} / \mathrm{v}, 0.02$ $\mathrm{mol} / \mathrm{L}$ ) in each well (within $1 \mathrm{~min}$ after addition of Arsenious acid solution) using multichannel pipette. The mixture was left for $30 \mathrm{~min}$ at $25^{\circ} \mathrm{C}$. Finally, absorbance was measured at $405 \mathrm{~nm}$ with a microtitre plate reader.

\section{Standard iodine standard solution $(100 \mu \mathrm{g} \mathrm{I} / \mathrm{ml})$}

From stock solution $\left(168.8 \mathrm{mg}\right.$ of $\mathrm{KIO}_{3}$ per $100 \mathrm{~mL}$ ), working solutions of $25-600 \mu \mathrm{g} \mathrm{I} / \mathrm{mL}$ were prepared by diluting with distilled water.

\section{Qualitative analysis of salt iodine content}

Measurement of salt iodine content was carried out by MBI rapid test kit. Two drops of test solution were added on the surface of the salt from the white ampoules by gently squeezing. Color on the salt was compared with the color chart. Iodine content in salt was determined by comparing color between salt and color chart.(No colorNo iodine; Light blue color $<15$ ppm iodine ; Dark blue color $>15$ ppm iodine).

\section{Results and Discussion}

\section{Descriptive characteristics of school going children}

The mean age group of study population (202) was found to be $9.51 \pm 1.60$ years where as mean height was 130.20 $\pm 14.07 \mathrm{~cm}$ and mean weight was $26.74 \pm 6.90 \mathrm{~kg}$.

Socio-demographic characteristic of house hold of school going children

The majority of the school children were non-vegetarian $176(87.1 \%)$ and only $26(12.9 \%)$ were vegetarian.
Among them, $93.1 \%$ of house heads were literate and only $6.9 \%$ were illiterate. All the families had heard of the iodized salt (aayo nun) with two child logo whereas NIDDS survey, 2005 had shown that $82.3 \%$ in Eastern and Central Hills had heard, and IDD survey 2007 had shown that $83 \%$ of the study population in nation level

had heard about iodized salt. On the contrary, only $63.4 \%$ of households knew the importance of iodized salt as compared to $75 \%$ of respondents of IDD survey 2007 . The religion distribution showed mixed composition with a higher percentage of Hindu (59.9\%), followed by Buddhist (24.8\%), Kirat (11.4\%), and Christian (8\%).

The survey showed, $51.5 \%$ of the family head engaged in Agriculture, followed by Business (29.75\%), Service $(11.9 \%)$, and other $(6.9 \%)$ respectively. Mean family size was $5.79 \pm 0.76$ and mean food secured months in a year was $11.25 \pm 1.32$ months. The survey revealed the fact that Goitrogenic food was not common in this study area. Gelal et al 2010, showed that in eastern hills, $16.5 \%$ of schools going children's were Iodine deficient.

\section{Type of salt for household consumption and livestock}

Out of 202 salt samples, 196 (97\%) used packet salt and 6 $(3.0 \%)$ open salt for their consumption in their households, which showed the greatest achievement of the availability of packet salt in that area. The availability of packet salt was only 3.8\% in Eastern Hills (NMSS, 1998) whereas the NIDDS survey 2005 reported $46.9 \%$ of study population in Eastern and central Hills used iodized packet salt. The IDD survey 2007 illuminated that the use of iodized packet salt was $29.0 \%$ in Eastern Hills.

Table 1

Iodine of salt content affecting by different factors

\begin{tabular}{|c|c|c|c|c|c|}
\hline \multirow[b]{2}{*}{ Statistics } & \multirow[b]{2}{*}{ Subgroup } & \multicolumn{3}{|c|}{ Iodine content of salt } & \multirow[b]{2}{*}{$\mathrm{P}$ value* } \\
\hline & & $>15 p p m(n=188)$ & $\begin{array}{l}<15 \mathrm{ppm} \\
(\mathrm{n}=11)\end{array}$ & $\begin{array}{r}0 \mathrm{ppm} \\
(\mathrm{n}=3)\end{array}$ & \\
\hline & Air Tight Container & $180(95.7 \%)$ & $6(54.5 \%)$ & $1(33.3 \%)$ & \\
\hline Salt container & Open Container & $8(4.3 \%)$ & $5(45.5 \%)$ & $2(66.6 \%)$ & 0.001 \\
\hline Salt storage in kitchen & $\begin{array}{l}\text { Shelf } \\
\text { Window Plane } \\
\text { Near Fire }\end{array}$ & $\begin{array}{l}152(80.9 \%) \\
18(9.6 \%) \\
18(9.6 \%)\end{array}$ & $\begin{array}{l}2(18.2 \%) \\
6(54.5 \%) \\
3(27.3 \%)\end{array}$ & $\begin{array}{l}1(33.3 \%) \\
2(66.7 \%) \\
0(0.0 \%)\end{array}$ & 0.001 \\
\hline
\end{tabular}


Table 2

Comparison of UIE among different demographic characteristics.

\begin{tabular}{|c|c|c|c|c|c|}
\hline \multirow{2}{*}{ Group } & \multirow{2}{*}{ Subgroup } & \multicolumn{3}{|c|}{ UIE $(\mu \mathrm{g} / \mathrm{L})$} & \multirow{2}{*}{ P Value* } \\
\hline & & Median & Percentile 25 & Percentile 75 & \\
\hline \multirow{2}{*}{ Dietary habit } & Veg & 172.95 & 102.52 & 248.44 & \multirow{2}{*}{0.394} \\
\hline & Non Veg & 145.17 & 78.75 & 212.09 & \\
\hline \multirow{2}{*}{ Education status } & Literate & 158.10 & 90.86 & 217.94 & \multirow{2}{*}{0.327} \\
\hline & Illiterate & 83.55 & 61.88 & 239.39 & \\
\hline \multirow{2}{*}{ Importance } & Yes & 149.81 & 88.97 & 209.21 & \multirow{2}{*}{0.838} \\
\hline & No & 160.51 & 72.41 & 233.10 & \\
\hline \multirow{2}{*}{ Livestock } & Yes & 196.61 & 145.17 & 242.59 & \multirow{2}{*}{0.015} \\
\hline & No & 139.49 & 75.10 & 210.65 & \\
\hline \multirow{2}{*}{ Type of salt for household } & Packet salt & 159.30 & 86.14 & 220.91 & \multirow{2}{*}{0.041} \\
\hline & Open salt & 83.55 & 61.88 & 133.91 & \\
\hline \multirow{3}{*}{ Type of salt for livestock } & Packet Salt & 94.69 & 94.69 & 116.74 & \multirow{3}{*}{0.067} \\
\hline & Open Salt & 142.88 & 74.20 & 212.09 & \\
\hline & Buddhist & 128.45 & 76.01 & 206.35 & \\
\hline \multirow[t]{3}{*}{ Religion } & Kirat & 92.77 & 61.88 & 203.53 & \multirow[t]{3}{*}{0.030} \\
\hline & Christain & 161.24 & 78.29 & 203.65 & \\
\hline & Hindu & 174.15 & 102.52 & 233.10 & \\
\hline
\end{tabular}

\section{Type of salt for household consumption and livestock}

Out of 202 salt samples, 196 (97\%) used packet salt and 6 $(3.0 \%)$ open salt for their consumption in their households, which showed the greatest achievement of the availability of packet salt in that area. The availability of packet salt was only $3.8 \%$ in Eastern Hills (NMSS, 1998) whereas the NIDDS survey 2005 reported $46.9 \%$ of study population in Eastern and central Hills used iodized packet salt. The IDD survey 2007 illuminated that the use of iodized packet salt was $29.0 \%$ in Eastern Hills.

\section{Type of salt used for livestock in household}

Out of 202 samples, 34 (16.8\%) had no livestock in their households, the remaining $163(80.7 \%)$ households used open salt for livestock and only $5(2.5 \%)$ used packet salt for their livestock. This finding was comparable with the finding of NIDDS survey, 2005 in Eastern and central Hills in which $20.4 \%$ of households used iodized salt and $44.4 \%$ used open salt for live stocks.
Salt related practices in household of participants

Salt practices in household varied widely in respect to their container used for storing, place of storing in kitchen, and time of adding salt in food while cooking. All these factors directly or indirectly affect the iodine content in salt and its availability for us. Majority, 126 (62.4\%) added salt in food in the beginning while cooking food,

only a few $9(4.5 \%)$ added at the end, and rest of the household added in the middle of the cooking. Most of the households $155(76.7 \%)$ used a wooden shelf to store salt while remaining kept near fireplace $(10.39 \% /)$ and in window plane $(12.87 \%)$. The majority of household 187 $(92.6 \%)$ used air tight containers for storage of salt and $15(7.4 \%)$ used open for storage.

Salt iodine content (SIC) of salt samples tested by rapid kit test

The household consuming adequately iodized salt ( SIC $>15 \mathrm{ppm}$ ) were $93.1 \%$, whereas $5.4 \%$ ( SIC $<15 \mathrm{ppm}$ ) and $1.5 \%$ household were using salt having SCI 0 ppm .

Table 3

Comparison of UIE among different salt using practices

\begin{tabular}{|c|c|c|c|c|c|}
\hline \multirow[t]{2}{*}{ Group } & \multirow[t]{2}{*}{ Subgroup } & \multicolumn{3}{|c|}{ UIE $(\mu \mathrm{g} / \mathrm{L})$} & \multirow[t]{2}{*}{ P Value } \\
\hline & & Median & Percentile 25 & Percentile 75 & \\
\hline \multirow[t]{2}{*}{ Salt container } & Air Tight Container & 159.30 & 87.07 & 220.91 & \multirow[t]{2}{*}{$0.189 *$} \\
\hline & Open Container & 51.72 & 51.72 & 51.72 & \\
\hline \multirow[t]{3}{*}{ Salt storage in kitchen } & Shelf & 152.15 & 81.49 & 217.94 & \multirow[t]{3}{*}{$0.883 * *$} \\
\hline & Window Plane & 138.39 & 92.77 & 220.91 & \\
\hline & Near Fire & 187.14 & 90.86 & 212.09 & \\
\hline \multirow{3}{*}{$\begin{array}{l}\text { Time of adding salt } \\
\text { while cooking }\end{array}$} & Beginning & 158.10 & 76.01 & 223.91 & \multirow[t]{3}{*}{$0.301 * *$} \\
\hline & During & 159.30 & 94.69 & 212.09 & \\
\hline & At the End & 90.86 & 49.71 & 145.17 & \\
\hline
\end{tabular}

**Kruskal Wallis test was applied to test the statistical significance between the groups; *Mann Whitney U test was applied to test the statistical significance between the groups. 
NMSS, 1998 reported that $50.6 \%$ salt samples from the Eastern Hills had adequate iodine but NIDDS, 2005 found the only $63.4 \%$ salt samples from Eastern and Central Hills were adequately iodized. Adequately iodized salt was present in $77 \%$ of households in 2006 and $80 \%$ of households in 2011(MOHP, 2005). The adequately iodized salt was $81.3 \%$ in Dhankuta and $89.6 \%$ in Dharan (Gelal et al., 2009).Also this study illuminated the fact that Eastern Nepal is continuously progressing towards the sustainable elimination of iodine deficiency disease as illustrated by a normal median UIE and the majority of households consuming adequately iodized packet salt.

\section{Median urine iodine excretion (UIE)}

Median UIE of the study population was $152.14 \mu \mathrm{g} / \mathrm{L}$ which indicated the adequate iodine intake and optimal iodine status of the population. Iodine status of the area was lower than the result of a national survey and the study conducted in western Nepal. The median UIE measured at a national level was $193.10 \mu \mathrm{g} / \mathrm{L}$ (Gelal et al., 2009); at Dharan city was $157.1 \mu \mathrm{g} / \mathrm{L}$ (Gelal et al., 2010); Dhankuta and Sunsari districts were $238.00 \mu \mathrm{g} / \mathrm{L}$ and $294.96 \mu \mathrm{g} / \mathrm{L}$ respectively (Chaudhari et al., 2012).

\section{Iodine status of the school going children}

The proportion of school children (fig. 1) with some degree of iodine deficiency (UIE $<100 \mu \mathrm{g} / \mathrm{L}$ ) is $30.7 \%$ $(n=62)$ which is comparable $(25.3 \%)$ to all hills reported in NMSS 1998 in all Hills, 27.3\% in eastern and Central Hills in NIDDS, 2005 and $18.9 \%$ in Eastern Terai in IDD survey 2007. According to Gelal et al 2009, in school going children in Dhankuta and Dharan district of eastern Nepal found that $22.0 \%$ of the study population had shown to be iodine deficient (UIE $<100 \mu \mathrm{g} / \mathrm{L}$ ). Gelal et al 2010 , showed that in eastern hills, $16.5 \%$ of schools going children's were Iodine deficient.

\section{Factors affecting salt iodine content (SIC)}

From chi-square test analysis, it was found that there is a statically significant $(\mathrm{p}<0.001)$ association between a salt container and SIC i.e salt samples stored in air tight container had a higher amount of iodine as compared to open container. Statically significant $(\mathrm{p}<0.001)$ association was found between the place of salt storage in kitchen and iodine content of salt. There's a significant $(p<0.5)$ difference between salt iodine content in the salt samples stored in shelf as compared to the window plane and near fine. Salt containers stored in the shelf had a higher concentration of iodine as compared to salt stored in window planes or near a fire.

\section{Factors affecting urinary iodine excretion Demographic factors affecting urinary iodine excretion}

The Mann Whitney test revealed that the households having livestock $(\mathrm{P}=0.015)$, type of salt for households $(\mathrm{p}=0.041)$, and religion $(\mathrm{p}=0.03)$ was significantly associated with median UIE. While there was no significant association between annual dietary habit $(\mathrm{P}=0.394)$, parents' educational status $(\mathrm{P}=0.0327$, knowing the importance of iodized salt $(\mathrm{P}=0.388)$, and type salt for livestock ( $\mathrm{P}=0.067)$ with median UIE. (table 2$)$.

\section{Salt using practices affecting urinary iodine concentration (UIE)}

The time of adding salt while cooking $(p=0.301)$ and place of salt storage in the kitchen $(p=0.883)$ salt container $(\mathrm{p}=0.626)$ were not significantly associated with UIE.(table 3).

\section{Association between salt iodine content (SIC) and urine iodine excretion (UIE)}

There was a significant $(\mathrm{p}=0.025)$ correlation between iodine intake (indicated by the SIC consumed) and UIE. UIE level increases among individuals consuming salt that contain more iodine. The median UIE level was high among school going children from households consuming adequately iodized salt. (table 4 )

Table 4

Association between SIC and UIE

\begin{tabular}{lccc}
\hline Statistics & Categories & $\begin{array}{c}\text { Median } \\
\text { UIE } \\
(\boldsymbol{\mu g} / \mathbf{L})\end{array}$ & P Value** \\
\hline & $>15 \mathrm{ppm}$ & 159.30 & \\
$\begin{array}{l}\text { Iodine content } \\
\text { of salt }\end{array}$ & $<15 \mathrm{ppm}$ & 133.91 & 0.025 \\
& $0 \mathrm{ppm}$ & 92.77 & \\
\hline
\end{tabular}

**Kruskal Wallis test was applied to test the statistical significance between the groups

\section{Conclusion}

The majority of the school children consumed packet salt (97\%) and the household with salt iodine concentration $>15$ ppm. was 93.1\%; which shows the greatest achievement of the availability of packet salt in that Suryodaya Municipality, Ilam. The iodine content of the salt and Urine Iodine Excretion (UIE) were significantly associated. The time of adding salt while cooking, place of salt storage in the kitchen, and salt container type are not significantly associated with UIE. Salt stored in air tight containers had a higher amount of iodine as compared to open containers. Similarly, salt stored in the shelf of the kitchen showed higher iodine content then salt kept in window plane and near a fire. The survey revealed the fact that Goitrogenic food was not common in the study area, therefore there was no effect of goitrogenic food in median UIE. The findings of this study are of great importance as they identify potential actions that can be taken for the improvement of iodine status children. A number of populations at this municipality still uses crystal salt which is insufficient in iodine. Awareness about the importance of iodized salt is required in areas.

\section{References}

Biswas, A.B., Chakraborty, I., Das, D.K., Roy, R.N., Ray, S. and Kunti, S.K. (2006). Assessment of iodine deficiency disorders in Purulia district, West Bengal, India. Journal of tropical pediatrics, 52 (4), 288-292.

Gelal, B., and Baral, N. (2010).Moving towards the sustainable elimination of IDD in Nepal.IDD Newsl, 36 (2), 12-14.

Gelal, B., Aryal, M., Lal Das, B. K., Bhatta, B., Lamsal, M., and Baral, N. (2009). Assessment of iodine 
nutrition status among school age children of Nepal by urinary iodine assay. Southeast Asian Journal of Tropical Medicine and Public Health, 40 (3), 538.

Ministry of Health \& Population, Child Health Division ,Micronutrient Initiative and New Era (2005). "Nepal Iodine Deficiency Disorders Status Survey, 2005".

Ministry of Health \& Population, Child Health Division, HMG/N, New Era, Micronutrient Initiative and UNICEF Nepal (1998).“Nepal Micronutrient Status Survey 1998". Kathmandu, Nepal.

Ministry of Health \& Population, Child Health Division, Micronutrient Initiative and New Era (2005)."Nepal Iodine Deficiency Disorders Status Survey, 2005".

Ministry of Health \& Population, Child Health Division, The Micronutrient Initiative, New Era (2005). "Iodine deficiency disorders status survey 2005 (Revised Print)". Kathmandu, Nepal.

Ministry of Health \& Population, Department of Health Services, Government of Nepal, Government of India (2007). "National Survey and Impact study for Iodine Deficiency Disorders (IDD) and availability of iodized salt in Nepal".

United Nations Children's Fund (2002). Iodine Deficiency Disorders and Universal Salt Iodization: South Asia Priorities.

United Nations Childrens Fund (WHO/ICCIDD/UNICEF) (2007). "Assessment of the iodine deficiency disorders and monitoring their elimination. Geneva: World Health Organization".

WHO,UNICEF, ICCIDD (2007). Assessment of iodine deficiency disorders and monitoring their elimination: a guide for programme managers. France.

WHO, UNICEF, ICCIDD. Assessment of iodine deficiency disorders and monitoring WHO (1993). Iodine and health: eliminating iodine deficiency disorders safely through salt iodization, a statement by the World Health Organization. p.p. 7.

World Health Organization, International Council for the Control of the Iodine Deficiency Disorders and United Nations Childrens Fund (WHO/ICCIDD/UNICEF) (2007). "Assessment of the iodine deficiency disorders and monitoring their elimination". Geneva: World Health Organization. 